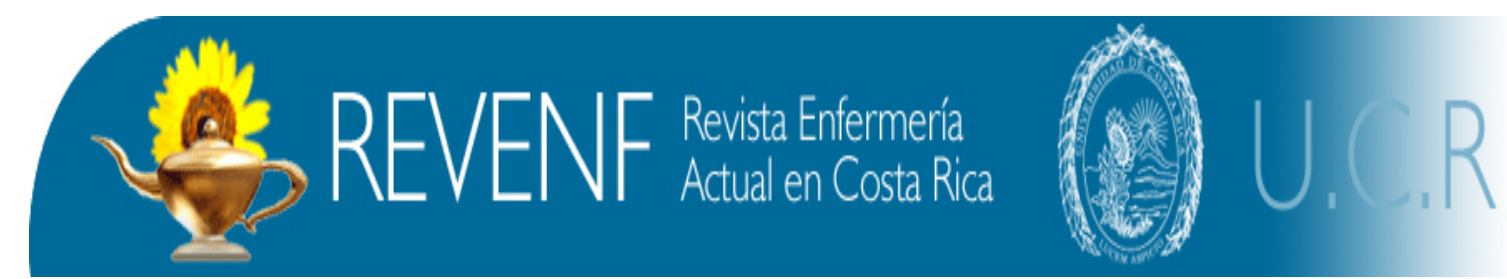

Revista Semestral Número 8 Año 4, Abril - Set.2005

ISSN1409 - 4568

\title{
CONSIDERACIONES PSICOLÓGICAS SOBRE LA HIPNOSIS APLICADA AL MANEJO DEL DOLOR ${ }^{1}$
}

Autor: Walter Vargas Valverde ${ }^{2}$

\begin{abstract}
RESUMEN
Se empieza con una breve reseña histórica sobre el desarrollo de la técnica hipnótica, algunas de sus definiciones y características observables en el paciente, hasta el diseño y aplicación de la sugestión.

Seguidamente se revisan investigaciones aplicadas al campo del dolor agudo y crónico, en donde se resaltan aquellas técnicas no farmacológicas, en especial la hipnosis.

Se discute sobre la efectividad de la hipnosis en el manejo del dolor. Se debe de diferenciar su aplicación entre niños y adultos.

Existe inconformidad entre los investigadores por la carencia de un instrumento objetivo y estandarizado para la medición del dolor tanto en niños, como en adultos.

La hipnosis se presenta como el instrumento más efectivo en el tratamiento del dolor y la ansiedad, y siempre debe de complementarse con el criterio médico y farmacológico.

Las esferas de influencia de la hipnosis, la relajación y la sugestión se traslapan, pues son parte de un continuo.
\end{abstract}

Palabras claves: Hipnosis y dolor, Técnicas no farmacológicas y dolor, Psicología y dolor Keywords: Hipnosis and pain., Non-pharmacology technique and pain, Psychology and pain.

\footnotetext{
${ }^{1}$ Fecha de recepción del original: Noviembre $2004 \quad$ Fecha de aceptación del original: Febrero 2005

${ }^{2}$ Maestría Académica en Psicología por la Universidad de Costa Rica. Labora como psicoterapeúta en su clínica privada, además de haber laborado en la Unidad de Quemados del Hospital Nacional de Niños. Sus intereses de investigación son: la psicoterapia, hipnosis clínica aplicada al dolor y el trauma psíquico. Alcoholismo y dependencia de sustancias.
} 


\section{ANTECEDENTES}

Paracelso (1493-1541) fue de los primeros que plantearon el efecto curativo de los cuerpos astrales y del imán (Kroger, 1974).

Federico Antonio Mesmer (1734-1815) en 1773, sustenta en Viena el “magnetismo animal” en el cual argumenta que la luna, el sol y las estrellas ejercen un influjo invisible sobre el cuerpo humano, el cual puede ser conducido por medio de imanes o limaduras de hierro, siendo el mismo Mesmer el intermediario de esas maravillosas fuerzas universales (Gindes, 1972; Kroger, 1974). Este procedimiento fue descalificado por una comisión investigadora en 1784, y se le trató de “charlatán”. Otros de sus seguidores fueron Petétin qsue habla por primera vez del estado catalítico; el marqués de Puységur quien mencionó por primera vez el “sonambulismo artificial” en donde los pensamientos y acciones del paciente quedaban subordinadas al hipnotizador.

Johamn Gassner (1727-1779) sacerdote Jesuita en el sur de Alemania. Creía en poder “expulsar los malos espíritus” del cuerpo de sus creyentes aprovechándose de las supersticiones de sus ignorantes fieles (Gindes, 1972).

El padre José Custodio de Faría (1756-1819) implementa en París entre 1814-1815 la inducción magnética, asegurando que las curas se deben a la expectación y cooperación del paciente. Faría rechazó los argumentos de Mesmer sobre el magnetismo animal y denominó como “sueño lúcido” lo que antes se consideraba como fenómenos magnéticos e introdujo lo que hoy se conoce como signo-señal que permite de manera instantánea provocar el estado hipnótico sin repetir pasos previos. Se sentaba frente al paciente y le pedía que fijara su mirada en sus manos y después le indicaba enérgicamente que se durmiera (Martínez \& Asís, 1985;Kroger, 1974).

En 1821 se registran los primeros datos de la hipoanestesia por medio de Recamier, en 
donde varias cirugías se hicieron bajo la guía mesmérica. Otros como Wheeler en USA y John Elliotson en Inglaterra siguieron los pasos de Mesmer en cirugías sin dolor (Kroger, 1974).

James Esdaile, cirujano escocés, entre 1840 y 1850 comunicó otra serie de operaciones quirúrgicas indoloras (Kroger, 1974).

James Braid, considerado el padre del hipnotismo moderno, desafió en 1841 el misticismo de Mesmer, probando que le cansancio de los lóbulos oculares generaba un estado semejante al del sueño (denominado método de fascinación). Fue el primero en demostrar que el sueño hipnótico puede ser provocado por agentes físicos y empleó la palabra “hipnotismo” que viene de la voz griega hypnos, que significa sueño. Braid aseguró que el grado de expectación incrementaba la susceptibilidad del paciente a la sugestión (Kroger, 1974;Gindes, 1972).

En 1876, Burcq, médico francés, le pidió al Dr. Claude Bernad, fisiólogo, que aplicara su terapéutica denominada “metaloscopía”, en donde el hierro se aplica a lesiones pustulantes, y el plomo en el corazón.

Liébeault de Nancy, considerado el fundador de la terapia sugestiva, trabajó junto a Hipólito Bernheim, neurólogo de Nancy. Ambos desarrollaron las teorías de Braid aplicándolas a más de doce mil pacientes, concluyendo que la hipnosis era una función del comportamiento normal e introdujeron el concepto de sugestión y sugestibilidad (Kroger, 1974).

Charcot (1856-1939), neurólogo de la Academia Francesa de Ciencias, defendía que la hipnosis era una forma de histeria, aunque sus estudios se basaron en una docena de individuos. Para él no fue comprensible que ciertos grados de sugestionabilidad pueden ser inducidos en la mayoría de las personas y que las respuestas hipnóticas son parte de la 
subjetividad y no accidentes dramáticos. En conjunto con sus alumnos demostró que existen varios grados de sueño hipnótico.

Janet (1859-1947) demostró que la hipnosis puede ser utilizada en la exploración intensiva de la personalidad (Kroger, 1974).

Freud (1976) indica que la hipnosis puede ser aplicable a la mayoría de la gente sana, aunque abandona su práctica cerca de 1856. La sugestión fue entendida como el influjo psíquico directo del médico sobre el paciente, así como el desencadenamiento de funciones del sistema nervioso a partir de esas sugestiones.

\section{DEFINICIÓN DE HIPNOSIS}

La hipnosis tiene su asentamiento en la zona inconsciente en donde el hipnólogo "siembra” las sugestiones (De La Fuente Muñiz, 1968; Gindes, 1972; Yans, 1974; Hewitt, 1989; Hadley \& Staudacher, 1994; Alvarenga, 1996).

Martínez \& Asís (1989) la definen como un estado alterado de conciencia en el cual las sugestiones se incorporan de manera automática.

Hewitt (1989) la define como una técnica que reduce el ciclaje del cerebro hasta Alfa, y aquí, el subconsciente es receptivo de los mensajes sugestivos.

Las ondas cerebrales presentan los siguiente registros (Hewitt, 1989; Alvarenga, 1996):

a-) Delta: la frecuencia es de 1 a $3 \mathrm{~Hz}$ ( Hercio, es la frecuencia de un movimiento vibratorio que ejecuta una vibración cada segundo). Es la inconciencia total.

b-) Theta: la frecuencia va de 4-7 ciclos por segundo. Es parte del estado subconsciente, aquí opera la hipnosis.

c-) Alfa: la frecuencia va de 7-14 ciclos por segundo. Aquí opera mayormente la hipnosis.

d-) Beta: región consciente, y su rango de frecuencia va de 14-20 Hz. 
Las etapas del sueño hipnótico (Martínez \& Asís, 1989) son:

a-) Hipnosis simple: se mantiene una zona de vigilia por medio en la cual se sostiene el rapport con el hipnotizador.

b-) Hipnosis media: aparecen husos Alfa, luego desaparecen, con debilitamiento del ritmo Beta y de la actividad eléctrica del cerebro.

c-) Hipnosis profunda: aparece el ritmo Theta de bajo voltaje, y desaparecen los ritmos Alfa y Beta típicos de la vigilia.

Debido a lo anterior, se considera la hipnosis como un estado especial de sueño, intermedio entre la vigilia y el sueño paradójico.

Las semejanzas entre el sueño fisiológico y el estado inducido por hipnosis (Martínez \& Asís, 1989) son:

1-) Son estados de la conciencia.

2-) Inhibición cortical parcial.

3-) Existe una línea contínua entre la hipnosis y el sueño, pues se puede pasar del primero al segundo. Aunque paradójicamente se usa la referencia al sueño fisiológico para entrar en trance.

4-) Los registros electroencefalográficos se asemejan a los del sueño paradójico.

5-) Se mantienen zonas de vigilia.

6-) Se presentan movimientos rápidos de los ojos cuando se le indica que sueñe o imagine.

7-) Disminuye el tono muscular.

8-) Disminuye el funcionamiento metabólico, la respiración, y la frecuencia cardíaca.

9-) Descenso ante los estímulos luminosos rítmicos.

Las diferencias entre el sueño fisiológico y el estado inducido por hipnosis (Martínez \& Asís, 1989) son: 
1-) La actividad eléctrica es distinta.

2-) Es un estado de hipersugestibilidad.

3-) Se provocan fenómenos como la catalepsia general, la anestesia y otros.

4-) Los cambios bioléctricos en el sueño fisiológico llegan a una frecuencia de 1-3 Hz, que no se ven en el sueño hipnótico.

Los grados y fenómenos psicológicos de los trances (De La Fuente Muñiz, 1968; Gindes, 1972; Hadley \& Staudacher, 1994; Alvarenga, 1996) son:

a-) Superficial: somnolencia, respiración y pulso un poco más lento y dificultad para oponerse a las sugestiones y puede que un acontecimiento imaginario lo considere como posible o imposible, además tiene conciencia de lo que ocurre a su alrededor.

b-) Medio: pérdida de la conciencia del medio y aumenta la conciencia de las funciones internas como la respiración y los latidos del corazón, la fantasía aumenta, aparece la catalepsia, amnesia, anestesia superficial, regresión con fines analíticos y ejecuta órdenes presentes y post-hipnóticas.

c-) Profundo: incluye los fenómenos del trance superficial y medio. Se da la pérdida de la receptividad auditiva y conciencia del medio, se intensifica el proceso creativo, además alucinaciones positivas y negativas, aparecen los indicadores del sueño.

El grado de sugestionabilidad varía de persona a persona.

La instauración de la palabra clave o señal, permite activar automáticamente el estado condicionado de trance (Yans, 1974; Martínez \& Asís, 1989; Hadley \& Staudacher, 1994). Toda persona que ingresa en hipnosis, logra salir de dicho estado con ayuda del terapeuta o por si misma (Gindes, 1972; Yans, 1974; De La Fuente Muñiz, 1968; Hewitt, 1989; Barone y Madorla, 1994; Alvarenga, 1996).

La fe y la expectación son indispensables en el paciente, pues se debe de confiar en la 
técnica y validez de los fenómenos hipnóticos, así como tener confianza en la integridad del terapeuta, y estar convencido de que podrá sanarse de padecimiento que le aqueja (Gindes, 1972; De La Fuente Muñiz, 1968; Alvarenga, 1996; Kroger, 1974).

La ecuación del éxito (Hadley \& Staudacher, 1994) es llamada la relación establecida entre imaginación x motivación $=$ fe + expectación. El procedimiento por medio del cual se ejecuta la ecuación se denomina inducción.

Al aplicar la técnica se deben de tener en cuenta los siguientes aspectos (Hadley \& Staudacher, 1994):

a-) Un estilo de inducción ( fijación de la mirada en un punto fijo ).

b-) Una técnica hipnótica permisiva, con suave tono de la voz y en acuerdo, apoyo al paciente.

c-) La voz del hipnotizador puede ser rítmica en donde se pone énfasis a las frases y palabras, o puede ser monótona en donde se carece de inflexión.

d-) La inducción puede seguir la siguiente secuencia: respiración profunda + relajación sistemática del cuerpo + creación de imágenes de relajación profunda + profundizar el trance hasta llegar al lugar ideal + finalizar la inducción y recuperar el nivel de vigilia usual.

Existen dos técnicas para ejecutar el proceso de inducción (Hadley \& Staudacher, 1974) la autoritaria y la permisiva. Las sugestiones pueden ser así:

a-) Sugestiones de relajación: le permiten asimilar las instrucciones y sugestiones de relajación física.

b-) Sugestiones de profundización: le permite profundizar en el trance concentrándose en una actividad.

c-) Sugestiones directas: no requiere de la imaginación, se responde más a las palabras que 
a las imágenes.

d-) Sugestiones de imágenes: crean imágenes para ser aprovechadas en otros escenarios.

e-) Sugestiones indirectas: se construyen con metáforas y símiles.

f-) Sugestiones post-hipnóticas: se hacen durante la inducción y se ejecutan al finalizar la misma. La sugestión se incorpora al inconsciente.

Se recomienda usar un lenguaje apropiado al contexto psicosocial y educacional del paciente (Hadley \& Satudacher, 1994). Algunas recomendaciones para el hipnólogo son:

a-) Haga sugestiones simples y claras.

b-) Repita las sugestiones.

c-) Las sugestiones deben de ser creíbles y deseables para el paciente.

d-) Construir un marco temporal para las sugestiones, y con ello el paciente puede ejecutar acciones para alcanzar sus metas.

e-) Limite las sugestiones a un área problemática a la vez.

f-) Se con trabaja a pasos progresivos.

h-) Use palabras positivas, evite las negativas.

i-) Evite sugestiones de relajación que generen pensamientos: primero se relaja el cuerpo, después se estructuran las cogniciones.

j-) Use palabras clave.

k-) Use imágenes para fortalecer sugestiones directas y órdenes post-hipnóticas.

l-) Desactive sugestiones que pueden generar efectos secundarios: por ejemplo, quedarse dormido mientras conduce el auto.

\section{RELAJACIÓN, IMAGINERÍA E HIPNOSIS}

Cordero \& Vargas (1991) en su intervención con niños quemados abarcan el internamiento 
y la consulta externa. Durante el internamiento aplican la estrategia de preparación, que le permite al paciente ajustar sus expectativas ante los procedimientos quirúrgicos, así como reestructuraciones cognitivas. Intervinieron de manera temprana a esta población.

Los tres pasos en este orden, permiten que el paciente ingrese satisfactoriamente al trance, y desde ahí se pueden operar una serie de sugestiones y diseñar herramientas psicológicas (Vargas, 2000).

La intervención con niños quemados de Vargas (2000) evidenció la dificultad de seguir la secuencia: relajación + imaginería + hipnosis $(\mathrm{RIH})$. Las dificultades radicaban en la aplicación reciente o inmediata de anestesia para un procedimiento médico, o debido a un dolor agudo en la parte quemada, en estos casos hay que proceder creativamente y adaptarse a la condición del niño (a), por ejemplo, captando su atención con indicaciones indirectas para que cierre los ojos e inmediatamente diseñarle directivamente algunas imágenes y tratar de acceder a algún tipo de trance.

La técnica de relajación en niños quemados no se puede aplicar sistemáticamente, ni de manera progresiva, y en ocasiones ni se puede aplicar.

La imaginería requiere de un terapeuta creativo y con experiencia en el trabajo infantil con niños (as) que experimentan dolor agudo, crónico, y que pueden estar mutilados físicamente (Vargas, 2000).

La implementación de la RIH viene acompañada por conteos antes, durante y al finalizar el ejercicio. Estos conteos tienen el objetivo de hacer transiciones de un estado usual de vigilia hacia la hiperconcentración.

Cautela \& Groden (1985) plantean que la técnica de relajación Jacobson, lleva a un estado pasivo o con ausencia de activación, lo que se manifiesta tres niveles: fisiológico, conductual y subjetivo. Consideran que los niveles conductual y subjetivo dependen del 
fisiológico.

La técnica Jacobson se basa en lo siguiente:

a-) Es una técnica fisiológica basada en la relajación de la musculatura esquelético-motora.

b-) Se basa en la discriminación de las señales de tensión en los distintos músculos del cuerpo por medio de ejercicios repetitivos y progresivos de tensión-distensión.

c-) La relajación de la musculatura-esquelético-motora desencadena relajación del sistema autonómico-vegetativo y la relajación del sistema nervioso central.

d-) La relajación fisiológica produce relajación emocional y de relajación cognitiva.

Los grupos musculares que se ejercitan son: frente, ojos, nariz, sonrisa, lengua, mandíbulas, cuello, brazos, piernas, espalda, tórax, estómago, nalgas y extremidades inferiores.

Se recomienda mantener tensa cada parte del cuerpo al menos cinco segundos y sentir la relajación al 10 segundos, su duración es de 15 minutos. Se asocian inhalaciones y exhalaciones lentas y profundas al final del ejercicio.

En niños menores de 8 años, se deben de considerar los siguientes aspectos: se puede cambiar la secuencia y se tensan y relajan grandes áreas corporales; se necesita más de una sesión; se pueden usar reforzadores como comida, fichas, y sonrisas, caricias, halagos. Se debe de evaluar si el niño toma algún medicamento que interfiera con la relajación.

\section{EJERCICIO DE KOEPPEN.}

Este ejercicio fue traducido y adaptado por Hernández \& Rodríguez (S.F.), el cual fue elaborado por Koeppen en 1974.

El rango de edad para su aplicación va de cuatro a trece años, aunque se pude aplicar en adolescentes y adultos con retardo mental. 
Es un método de relajación neurofisiológica, dado que se entrena sistemáticamente a relajar y contraer los grupos musculares, es muy parecido al ejercicio de Jacobson.

Las partes del cuerpo involucradas son: frente, nariz, boca, cuello, hombros, brazos, manos, glúteos, músculos del abdomen, muslos y pantorrillas.

Algunas consideraciones para su ejecución son: modelarle al niño (a) cómo se hace cada ejercicio; los grupos musculares se contraen y relajan de tres en tres; debe de estar acostado sobre una colchoneta; al final del ejercicio se debe de regresar al niño (a) a su estado de vigilia calmadamente; su duración es de veinte minutos.

El lenguaje empleado puede ser tierno, condescendiente y mágico, asociándose con imágenes de animales, riachuelos y frutas para estimular la acción.

\section{EJECUCIÓN DE LA TÉCNICA HIPNÓTICA EN NIÑOS Y NIÑAS}

Ser rápido y ágil, pues los niños se encuentran predominantemente en estado Alfa, por ello no es necesario aplicar ejercicios de pre-hipnosis, se puede usar el contacto físico (en vista de los posibles abusos sexuales de algún perverso, es recomendable que el terapeuta esté acompañado de algún auxiliar o familiar del niño) y visualizar una parte de su cuerpo que se encuentre enferma o con dolor, y corregirle (Hewitt, 1989).

Un $80 \%$ de niños atendidos en servicios de emergencias se han beneficiado de estrategias hipnoterapeúticas, por ello se recomienda su uso en el tratamiento del dolor agudo y crónico (Olness, 1989).

La hipnosis es más efectiva en el control del dolor que la relajación, pues el componente psicológico del dolor es el sufrimiento y esto es lo que aborda la hipnosis (Holroyd, 1993).

El parpadeo sincronizado se recomienda con niños, además, el uso del lenguaje sencillo y adecuado a la edad (Martínez \& Asís, 1985). 
Después de los 5 años de edad, los niños pueden ser inducidos hipnóticamente (Alvarenga, 1996).

Holroyd (1993) señala tres consideraciones al usar la hipnosis:

a-) La distracción, que busca captar su atención en acciones inmediatas.

b-) La disociación, en donde se le convence al paciente que su dolor está en otra parte del cuerpo, o que piense en otro lugar o tiempo.

c-) La sugerencia de confort y tranquilidad, usando metáforas y palabras mágicas, siendo la creatividad del terapeuta un recurso indispensable en el tratamiento de niños.

Vargas (2000) contra-argumenta a Martínez \& Asís (1985) pues él sí obtuvo buenos resultados con la aplicación del método de fascinación asociado al parpadeo sincronizado. Mientras Alvarenga (1996) recomienda el uso de la hipnosis en niños después de los 5 años de edad, Holroyd (1993) lo recomienda con buen resultado entre los 10 y 11 años de edad, en cambio Putnam (1991) refiere que entre más cortos de edad es efectiva hasta los 9 y 10 años, luego decrese su grado de hipnotizabilidad, finalmente Martínez \& Asís (1985) indican que entre los 3 y 7 años de edad se deben de usar métodos con estímulos monótonos que produzcan agotamiento (balanceo en un sillón, canciones infantiles suaves), y un segundo grupo entre los 8 y 12 años de edad, en donde el uso de videos con imágenes que produzcan sueño es efectivo, así como el pestañeo sincronizado. Yans (1974) considera que los niños (as) pueden entrenarse en Autohipnosis a partir de los 6 años de edad.

\section{HIPNOSIS APLICADA A QUEMADOS}

Rivlin (1988) señala el uso de la hipnosis, fármacos, terapia de juego, la musicoterapia, la 
psicoterapia, la manipulación ambiental y la educación como recursos en la intervención con los niños quemados. Se recomienda su uso en la fase aguda para aliviar el dolor.

Osgood \& Szfelbein (1989) refieren que la hipnosis es un medio no médico para el control del dolor, pero se detectan dificultades en la planeación, lo cual le ha quitado eficacia.

La hipnosis ha probado su eficacia en el manejo del dolor en distintas poblaciones (Bourne, 1994; Hadley \& Staudacher, 1994), específicamente provocando hipnoanalgesia durante los tratamientos por limpieza de quemaduras (Holroyd, 1996).

Long \& Cope (1961) realizaron un estudio muy completo de la población de niños quemados, se indica la importancia de la historia clínica del paciente, las características familiares, y antecedentes de la personalidad del niño. Al avanzar el internamiento, los niños empezaron a mostrar conductas de rechazo ante los procedimientos médicos, y temor hacia el personal médico-enfermería que le atendía. Los investigadores le dan importancia a los significados del accidente, la enfermedad, tanto en lo individual, como en lo familiar. Bowden \& Burstein (1990) señalan que los pacientes asustados experimentan más dolor que los que no lo están. El significado psicológico de la lesión o enfermedad impacta en los niveles de dolor, incluso la tensión y la angustia (en caso de pérdida o duelo) incrementan el dolor.

Benians (1989) indica que la visita de los parientes cercanos de los niños quemados constituye un factor relevante en su recuperación.

Patterson, Everett, Burns y Marvin (1992) cuestionan la efectividad de la hipnosis en niños quemados:

a-) Se concuerda en que la hipnosis es un tratamiento adjunto para el manejo del dolor en quemaduras.

b-) El personal que tiene a cargo pacientes con dolor, evidencia dificultades para reconocer 
el dolor de manera precisa.

c-) No hay un medio confiable para determinar si alguien está o no en un estado hipnótico.

d-) No se debe de sustituir la administración de opiodes por la hipnosis, para evitarle sufrimiento innecesario al paciente. La medicación se suspende cuando es peligrosa.

e-) Se cuestionan si es recomendable que la inducción esté a cargo de una persona o por una grabadora y con ello estandarizar el proceso de inducción.

Van der Does \& Van der Dyck (1989) señalan lo siguiente:

a-) Desde hace 30 años se viene usando la hipnosis en el tratamiento de quemaduras, lográndose mejorías en el alivio del dolor, en estimular el apetito, promover motivación y ejercitar partes del cuerpo quemadas.

b-) Sorprende que la hipnosis no se use ampliamente en las Unidades de Quemados.

c-) La hipnosis aplicada a quemados abarca tres áreas: aceleración de la curación de la herida; manejo del dolor; intervención en crisis.

d-) La intervención en crisis abarca los estados de conciencia que se suceden rápida y espontáneamente en aquellos pacientes aquejados de trauma o dolor agudo. Es así, como la hipnosis ha sido usada aprovechando aquellos trances espontáneos de la gente traumada y así contrarrestar los agudos sentimientos de ansiedad y pánico.

e-) La hipnosis favorece crear un ambiente relajado que neutralice los aspectos negativos de la crisis, logrando reenfocar la atención, mejorando la evocación de los recuerdos, aumentando la capacidad de producir fantasía, creatividad y sugestionabilidad.

f-) Se ha usado la hipnosis para rehabilitar pacientes quemados y pobres de USA, especialmente con Síndrome de estrés post-traumático.

g-) La hipnosis es capaz de influenciar la respuesta inflamatoria, aplicando la técnica dentro de las primeras cuatro horas de la lesión. 
h-) La hipnosis se emplea bilateralmente, en donde a una hemiparte del cuerpo se le aplica y a la otra no (ambas partes quemadas), y luego se comparan. Se buscan mejorías en la granulación de la lesión.

Kavanagh (1990) destaca la necesidad de instrumentar a los niños quemados para que participen en sus curaciones y otros procedimientos médicos.

Stoddard \& Norman \& Murphy \& Beardslee (1990) señalan que no existe un único tratamiento que ayude al niño quemado a enfrentar las secuelas psiquiátricas de la lesión, aunque concuerdan con Kavanagh en la importancia de instrumentar al niño en sus procedimientos médicos.

Kelly \& Lynch (1994) aseguran que desde el punto de vista clínico, la hipnosis es efectiva como tratamiento en el control del dolor, pero faltan estudios experimentales controlados para poder generalizar sus resultados. Otros métodos para el control del dolor son:

a-) La percepción del dolor se puede cambiar, se bloque su discriminación.

b-) Se sustituye la sensación dolorosa por otra diferente, menos dolorosa o más tolerable.

c-) Se desplaza la ubicación del dolor a otra zona psicológicamente menos vulnerable.

d-) Disociación del conocimiento del dolor, el paciente experimenta que el dolor lo vivió en otro estado, lugar o tiempo.

e-) El significado del dolor se puede cambiar.

f-) Se distorsiona el tiempo mientras se vive el dolor (más rápido).

Salas \& Chan Suen \& Wu Chen (1997) indican que la terapia conductual aborda el componente psicológico del dolor, en donde su objetivo principal es la disminución de la desesperación y el desamparo de los pacientes con cáncer. Agregan, que la hipnosis y la relajación son complementarias en el tratamiento del dolor.

Salas et. al. (1997) indican que existe mucha evidencia del uso de la hipnosis en el 
tratamiento del dolor agudo y crónico, con la limitante de que solo el 50\% de los pacientes logran cierto grado de analgesia.

Kittelberger \& LeBel \& Borssok ( 1999) indican que en la valoración del dolor se deb en de incluir los aspectos psicológicos, y señalan los siguientes puntos:

a-) La personalidad del paciente influye en la experiencia subjetiva y conductual ante el dolor.

b-) Algunos pacientes se benefician de estrategias de control, como la distracción y la relajación.

c-) Algunos desórdenes influyen en los pacientes con dolor crónico: la depresión mayor, desórdenes de somatización, de conversión, hipocondría, psicógenos.।

d-) Se debe diferenciar entre dolor psicógeno y la simulación.

Edwards (1999) señala que la ansiedad y gran tensión incrementan la experiencia del dolor, y ello empeora cuando el dolor es agudo, pues no se controla el entorno. Se indican las siguientes técnicas como auxiliares en el manejo del dolor: la relajación la persona se centra en una imagen o serie de imágenes; la respiración profunda contribuye a controlar sus niveles de ansiedad y la preparación para procedimientos dolorosos; la relajación muscular progresiva produce una respuesta fisiológica más intensa que es efectiva en el manejo del dolor crónico y la tensión postoperatoria.

Edwards (1999) señala dentro de las técnicas que guían la distracción, a la hipnosis y la abstracción de imágenes. Sobre la hipnosis, se resalta que la atención del paciente puede ser dirigida hacia sus pensamientos o bloquear, sustituir, cambiar u olvidar su dolor, aún así, se interroga sobre si su efecto es placebo.

Wolter \& Ahern (1999) reconsideran que para la valoración psicosocial del dolor se observe lo siguiente: 
a-) La entrevista clínica: se registra la experiencia dolorosa, así como la información que brinden otros familiares, el impacto del dolor en la pareja, la familia, lo laboral, lo educativo, lo interpersonal. Esta información se cruza con la historia clínica y pruebas psicológicas complementarias.

b-) Características del dolor: se usan registros objetivos del dolor, así como descripciones subjetivas del dolor para comprender su respuesta emocional.

c-) Comportamiento ante el dolor: el análisis de la información verbal y no verbal como respuesta al dolor, permite configurar el manejo subjetivo y su conexión con la conducta.

d-) Uso de medicamentos: se deben de determinar y valorar los patrones de uso longitudinalmente.

e-) Impacto laboral y económico: se debe de determinar cómo afecta el dolor el desempeño laboral, las relaciones interpersonales, y las consecuencias económicas. Identificar conflictos laborales que incrementen la respuesta al dolor.

Se recomienda el uso de la reestructuración cognitiva para la reinserción del paciente con dolor crónico.

f-) Incapacidad labora: el paciente puede hacer un auto-registro de aquellas actividades que se han visto afectadas por el dolor y cuáles no.

g-) Relaciones familiares y conyugales: determinar cómo afecta la funcionalidad y la dinámica conyugal-familiar e interpretar el significado del dolor en la familia y sus ganancias secundarias.

h-) Angustia emocional y alteraciones psicológicas: el grado y severidad del dolor, combinado con la condición psicológica del paciente previa, servirá para estudiar la adaptación psicológica y su sintomatología.

i-) Medidas del dolor: algunas escalas de autoregistro pueden ayudar en la valoración del 
dolor, incluso el uso del Cuestionario de personalidad mulitfásico de Minnesota (MMPI).

j-) Uso y reducción apropiada de medicamentos y reentrenamiento de la capacidad física, y relajación y control de la tensión.

LaCross \& Soumek (1999) señalan que en el tratamiento del dolor crónico el abordaje debe de ser interdisciplinario: terapeutas ocupacionales, asistentes sociales, consejeros en el manejo del estrés, consejeros vocacionales, preparadores físicos, enfermeras, un coordinador. Además, un psiquiatra que maneja la medicación psicotrópica y los desórdenes graves, y los psicólogos que ayudan en el manejo de la depresión.

LaCross \& Soumek (1999) que el manejo del dolor se puede hacer por medio de la relajación, respiración diafragmática, cambiar la percepción del dolor por medio de la reestructuración cognitiva y las afirmaciones.

Ballantyne \& Borssok (1999) indican que las técnicas de relajación y técnicas de imágenes y recuerdos ayudan a los pacientes en el control del dolor postoperatorio. Además, enfatizan en las diferencias entre el dolor de los niños y de los adultos, de acuerdo a lo siguiente:

a-) Los bebés y niños no asimilan los fármacos igual que los adultos.

b-) Los niños reaccionan con miedo y conducta inapropiada a los instrumentos médicos y de enfermería.

c-) Los métodos de tratamiento del dolor en niños varía según la edad: de 0 meses a 4 años no suministran información confiable del dolor; de 4 años a 8 años, pueden brindar información por medio de escalas visuales, o decirle a sus padres o a los médicos y enfermeras; los de 8 años pueden registrar su experiencia del dolor en escalas numéricas o visuales.

d-) El tratamiento del dolor en niños es insuficiente por la falta de mecanismos para su 
detección.

Dauber \& McPeek (1999) indican que el paciente quemado experimenta dolor agudo y crónico. El agudo es el más intenso y se presenta durante las curaciones, debridaciones y cambio de vendajes. Después de la curación, mientras el paciente reposa, se mantiene un dolor contínuo por días, semanas y meses. El dolor puede incrementarse por la ansiedad, la depresión, alteraciones del sueño y neuralgia posquemadura.

Dauber \& McPeek (1999) afirman que el paciente quemado necesita apoyo psicológico tanto en fase aguda y crónica. Se recomiendan las técnicas de imaginería, distractoras por medio de la música, biofeedback, estimulación nerviosa eléctrica transcutánea (TENS), todo ello en complemento con la medicación.

Fishman \& Greenberg (1999) indican que la ansiedad y la depresión son trastornos comunes en los pacientes con dolor, con mayor registro en el dolor crónico, los cuales se benefician de la aplicación de técnicas como la retroalimentación, la relajación, la hipnosis, desensibilización y modificación de la conducta.

Hewitt (1998) reafirma que la hipnosis sirve para el control del dolor agudo y crónico. Como paso previo, el paciente debe de aprender la auto-hipnosis, para lo cual se requiere haber sido hipnotizado por otra persona antes, así se instaura la cadena de aprendizajes.

Stokvis \& Wiesenhutter (1983) resaltan en su revisión, que la autosugestión es un elemento intrínseco de la heterosugestión, formando una unidad, registrada como una línea bipolar y contínua, pero que en si misma representa una dinámica de interpretación analítica de la existencia.

Se refieren a la sugestión como la influencia de una persona sobre otra, traspasando las esferas racionales de la personalidad o como la acción sugestiva de las imágenes con fuerte carga afectiva, que en el caso del psicoanálisis, el elemento sugestivo tendría su origen en 
el poder de los padres, y por ello el sugestionado ocuparía el lugar del niño. En fin, existen muchos criterios al respecto, pero se rescata que la (auto) sugestión basa su poder en la necesidad de contacto y de estar-en-comunicación del ser humano debido a su incompletitud, incapaz de existir solo.

Se sigue, que en la autosugestión se da una relación entre el yo y el si mismo, lo cual ha sido denominado como "auto-resonancia afectiva": el yo se apodera de una experiencia de la conciencia y se la "sugiere" al si mismo, en un segundo momento el yo se propone un cambio, para ello la "representación” debe de tener un significado afectivo si se realiza por él mismo, adquiriendo la representación la categoría de un producto mental, una acción o un impulso de la voluntad.

Continúan con que la relajación auto-sugestiva opera sobre un cuerpo que tiene significados psíquicos: si un órgano enferma afecta la experiencia, e inversamente, la experiencia afecta al órgano. Aquí opera el postulado de que la dirección de la atención se asocia al afecto.

Finalmente, Stokvis \& Wiesenhunter (1983) confirman que la influencia auto-sugestiva se testimonia en: el sistema de vasos sanguíneos; el aparato digestivo; órganos de la respiración; tracto urogenital; funciones genitales; el estado de la piel; las relaciones entre la percepción del dolor y el sistema nervioso vegetativo. Además, de registros de que la piel puede afectarse por medio de representaciones auto-sugestivas y de hipnosis.

Borenstein \& Seidman \& Tsur (1990) señalan que la auto-hipnosis fue lograda y asociada como complemento a la terapia analgésica y ansiolítica en 18 pacientes quemados. La auto-hipnosis es corta y barata, pues no requiere de personal especializado acompañando permanentemente al paciente antes de cada procedimiento doloroso. El procedimiento empleado concentró sus pensamientos hacia la creación de sentimientos de suavidad, liviandad en todo el cuerpo, y una vez lograda la relajación muscular, su imaginación fue 
dirigida hacia la situación eventual del tratamiento con el agua, en donde se imaginaba un sonido tranquilo, nadando, flotando, sumergiéndose en agua fresca. Con esto se pretendió aliviar el temor asociado al baño diario del cuerpo quemado. Logrado este nivel de profundidad hipnótica, los pacientes pudieron avanzar hacia la instauración de la disociación de si mismos en el procedimiento doloroso y se fijaron órdenes post-hipnóticas por medio de la fijación de un código personal, y paralelamente se instauró un código personal para activar el estado hipnótico automáticamente, y se colocó una orden posthipnótica para salir del trance.

De un total de 180 pacientes quemados, entre los 10 y 62 años de edad, y en un rango del 8\% al 70\% de superficie corporal quemada, solamente 148 lograron algún grado de relajación, pero solo 48 de ellos llegaron a la hipnosis lidiando con el dolor, y solamente 18 de este último grupo alcanzaron la auto-hipnosis.

La auto-hipnosis fue usada en 12 hombres y 6 mujeres entre 14 y 54 años.

Una limitación, radica en que no todos los pacientes lograron ingresar al estado hipnótico, y menos los que lograron la auto-hipnosis, especialmente, porque se requiere de un alto grado de autonomía personal y un yo fuerte, el cual no todos los pacientes tienen.

La relajación es previa a la hipnosis, y algunos la consideran un moderado estado hipnótico, además, determinaron que la técnica de relajación de Jacobson no fue apropiada y tuvo poco éxito en quemados.

Kleiger (2000) afirma que la hipnosis puede estar acompañada de relajación, y se caracteriza por la atención concentrada, la imaginación y la percepción restringida y los cambios en la sensación, percepción y fisiología. Recomiendan el uso de la hipnosis en un servicio de emergencias, y en particular para el manejo del dolor y quemaduras, como distractor, para alterar la sensación de la piel quemada con sugestiones de frescura durante 
las primeras horas y de tibiedad unas 24 horas después, y debe de ser un complemento a la analgesia.

Wright \& Drummond (2000) rescatan que la “rápida inducción de analgesia” (RIA) incluye sugestiones para reducir la tensión, ansiedad y sensaciones de dolor. En su investigación determinaron que RIA redujo el dolor y la angustia en los pacientes quemados, y se presenta como un recurso adjunto a los opiodes analgésicos durante los cuidados por quemadura.

Los beneficios terapéuticos incluyen una disminución de la angustia durante el cambio de vendajes, disminución en la ansiedad anticipatoria, incremento en los niveles de relajación, disminución en las solicitudes de medicamentos analgésicos y disminución en la intensidad del dolor durante y después de los cambios de vendajes.

Tucker \& Virnelli (1985) consideran que la hipnosis es un instrumento idóneo para asistir al médico en el manejo de cirugías plásticas y plantea lo siguiente:

a-) Un nivel satisfactorio de hipnosis se logra rápidamente.

b-) La susceptibilidad del paciente parece estar directamente relacionada con las necesidades del paciente.

c-) El hipnotista guía al paciente a utilizar la hipnosis y la auto-hipnosis en su beneficio.

d-) La hipnosis es un estado alterado de la conciencia que involucra a la relajación, en donde una persona concentra su atención sobre una idea o imagen que acepta por medio de sugestiones optimistas.

e-) La hipnosis en asocio con anestesia local es muy efectiva.

f-) El estilo de cada médico puede variar, algunos son más autoritarios y otros más permisivos.

g-) Las sugestiones indirectas pueden ser muy útiles previo a la administración de a 
anestesia local.

h-) Un ambiente calmo, sin estímulos negativos es efectivo.

i-) Las sugestiones deben de ser positivas.

j-) Una utilidad es la hipo-anestesia.

k-) El rango de edad va desde los 3 años hasta los 90 años. Parecen ser idóneos los niños entre los 4 y 12 años.

l-) En quemados es muy efectivo para aliviar el dolor durante el cambio de vendajes, para mejorar la participación del paciente en sus procedimientos dolorosos. Se recomienda aplicarla en las primeras 4 horas después de sucedida la quemadura para disminuir la inflamación y profundidad de la lesión.

Cruzado \& Labrador \& Puente \& Vallejo (1990) señalan que cerca de un $80 \%$ de las consultas médicas tienen que ver con el dolor. Algunas técnicas eficaces son: la relajación; biofeedback; tratamiento operante; técnica cognitivo-conductual; tratamiento operante. Sobre la relajación su importancia radica en orientar la atención fuera de la experiencia del dolor, reducir la ansiedad subjetiva, brindarle un instrumento al paciente que puede usar antes, durante y después de la experiencia dolorosa ( cuando es de baja intensidad ). Además describen seis aspectos a considerar para disminuir el dolor y la ansiedad en procedimientos con niños: edad y maduración cognoscitiva; locus de control, que refiere a la necesidad o no de que reciba sedantes y analgésicos; experiencia previa con procedimientos pediátricos; los estilos de afrontamiento individual; la preferencia de los progenitores al uso o no de medicamentos; el costo y disponibilidad de un psicólogo especializado en hipnosis e intervenciones cognitivo-conductuales con niños.

Zeltzer \& Jay \& Fisher (1989) señalan que el objetivo de las intervenciones psicológicas es disminuir la ansiedad e instrumentar al niño para afrontar procedimientos médicos. Se 
indican: preparación; hipnosis; terapia conductual; cognoscitiva-conductual. Destaca que el procedimiento de preparación, puede ser sensorial o dependiente. En el primer caso brinda al niño una descripción de las sensaciones en cinco sentidos, de lo que puede experimentar durante el procedimiento; la segunda hace una descripción del procedimiento, sin incluir las sensaciones. Sobre la hipnosis se menciona que ha sido útil en las aspiraciones de médula ósea (BMA) y en punciones lumbares (LP), inyecciones quimioterapeúticas, especialmente para la disminución de la ansiedad.

Selbst \& Henretig (1989) indican que es posible relajar a los niños desde los 3 años usando imaginación dirigida, aunque la anestesia total con cualquier técnica conductual es poco frecuente, por lo cual se debe de usar en complemento con criterios médicos. Consideran que el paciente que llega a la sala de urgencias lo hace en un estado hiper-sugestionable, por lo cual pueden ser receptivos a la hipnosis.

Chen \& Joseph \& Zeltzer (2000) indican que existen tres factores que influyen en la experiencia del dolor agudo en niños: sensibilidad al dolor; enfrentamiento; aspectos cognitivos. En relación a la sensibilidad, los niños presentan diferencias debido a su temperamento y se enfatiza en el diseño de un instrumento para medir el dolor. En relación al enfrentamiento cada niño tiene su preferencia natural sobre cómo lidiar ante los procedimientos, aunque se acuerda que brindarle información y distraerles es eficaz. En relación a los aspectos cognitivos se debe de tener en cuenta el nivel de desarrollo cognitivo , pues de ello depende el concepto de dolor y su capacidad de expresión para la medición del dolor.

Chen et. al. (2000) mencionan que los procedimientos más usados son: desensibilización; reforzamiento positivo; relajación; preparación; cambio de los recuerdos; hipnosis; detención del pensamiento y afirmaciones positivas; distracción; modelamiento y ensayo. 
Sobre la hipnosis el objetivo es dirigir la atención hacia otro punto, así como el uso de metáforas para controlar el dolor y disminuir la ansiedad, s recomienda el uso de la relajación progresiva.

Rusy \& Weisman (2000) indican que el tratamiento del dolor se logra complementando técnicas farmacológicas y cognitivo-conductuales. Se incluye a la hipnosis, la distracción, la sugestión, técnicas de respiración, imaginación guiada, relajación muscular progresiva y medidas de comodidad (en lactantes).

Resaltan que la hipnosis es más efectiva que otras técnicas. Se mencionan las técnicas de respiración toráxica en niños mayores y superficial en muy menores. Sobre la relajación muscular progresiva de Jacobson, se indica que es útil para reducir la tensión y ansiedad asociada al dolor. La sugestión en metáfora se implementa.

Mooney (1991) señala que el dolor es algo común para las enfermeras ortopédicas, se recomiendan intervenciones como: relajación, imaginación, distracción, hipnosis, estimulación transcutánea (TENS), música, tacto terapéutico, humor, acupuntura. Algunas consideraciones son: la etapa de desarrollo en la que se encuentra el paciente; se debe de suponer dolor en niños aunque no lo expresen abiertamente; el dolor es una experiencia nueva y difícil para niños pequeños; las enfermeras pueden apoyar a los niños y sus familiares en procesos dolorosos; nunca se debe de negar una analgesia por la variable edad; en caso de adictos a drogas, tienen el mismo derecho al control del dolor y se puede coordinar con especialistas en abuso de sustancias; hay que creer en el dolor del paciente y prevenirle.

Henry \& Foster (2000) indican que el personal que labora en quemados, debe de superar la falta de sensibilidad y la negación, como defensa. El tratamiento del dolor abarca la administración de analgésicos y ansiolíticos en complemento con una intervención 
temprana desde lo psicológico. Se recomienda el tratamiento cognitivo-conductual para manejar el dolor y la ansiedad que conforman el malestar, el cual es caracterizado por: temor, desconocimiento, separación, desorientación, pérdida de control, hipo e hipertemia, ansiedad y dolor.

\section{CONSIDERACIONES}

La relación entre la hipnosis, la relajación y las sugestiones, y el cuerpo humano, parece ser antiquísima, especialmente porque el dolor siempre nos a acompañado a lo largo de la evolución. Sabemos que la disociación mental es un recurso natural y espontáneo ante situaciones amenazantes.

Los primeros ejecutores de la hipnosis, basaban su efectividad en la atmósfera mística y religiosa que les rodeaban, y por supuesto la fe de la gente en ellos.

El desarrollo de la hipnosis logra condición científica cuando se libra de lo mágico, y se ingresa en la capacidad sugestiva de cada individuo.

En especial, la hipnosis clínica empieza a establecer relaciones entre los procesos fisiológicos y los psicológicos, así como las condiciones ambientales que rodean su ejecución. Se deben de analizar las variables socio-culturales del paciente.

Los trances, o mejor denominados como hiper-concentraciones, son factibles en la mayoría de las personas, solo que varían en intensidad y duración de persona a persona.

La sugestión es la base para alcanzar la profundidad hipnótica, por ello ésta debe de ser ejecutada por un experto, en especial por las consecuencias técnicas y éticas.

El factor fe, no es indispensable para la ejecución de la hipnosis en población afectada por el dolor, pues su condición psicológica los predispone a la heterosugestión.

Las definiciones de hipnosis tienden al acuerdo, en concreto por la dirección de la atención y su focalización, así como el uso de la sugestión como recurso para influir en el paciente 
hasta lograr un efecto terapéutico sobre el cuerpo. La relación mente-cuerpo parece retroalimentarse a cada instante, y se favorece con la hipnosis.

La tendencia es que la hipnosis tiene tres niveles de profundidad y que inicialmente opera desde las ondas Alfa.

Se concuerda que la hipnosis no es sinónimo de inconsciencia total, o falta absoluta de voluntad, por el contrario, el paciente siempre mantiene un punto de contacto con la realidad. No se observan contraindicaciones de su aplicación en población clínica que sufre de dolor, aunque no debe nunca sustituir a la farmacología en cualquier abordaje, especialmente con niños, por sus dificultades para demostrar el dolor experimentado.

El recurrir a sugestiones directas o indirectas dependerá del paciente, pero si se acuerda en el uso de sugestiones optimistas y centradas en el bienestar del paciente.

Al trabajar al sujeto con dolor y sufriente, se debe de discriminar su modalidad de ingreso sensorial, pues puede ser en alguno o todos los cincos sentidos, y esto determinará el tipo de imágenes a usar.

El ser permisivo o autoritario en la ejecución de las sugestiones, debe de ser valorado por el terapeuta cuando lidia con el paciente, aunque con niños es conveniente ser calmo, cariñoso, tierno, y fundamentalmente, mágico.

El diseño de la palabra clave, puede ser útil para ahorrarse tiempo en la inducción del trance, pero se debe de entrenar varias veces para estar seguro de su aprendizaje. Dependiendo de la efectividad de la profundidad hipnótica, el paciente puede discriminar la utilidad del trance, pero se debe de considerar que muchos de estos pacientes pueden estar medicados en el momento de la ejecución hipnótica, lo cual puede influir en un buen aprendizaje.

El profesional en ciencias de la salud y de ciencias sociales, como la psicología, que desee 
usar estas técnicas, debe de someterse a un entrenamiento personal, ya sea de investigación, así como de experiencia personal. Además, debe de ser hábil con la palabra, mágico, fabulesco, y de buen humor.

Un ejercicio que debería de ejecutar un hipnólogo, es diseñar espontáneamente escenarios imaginarios, pues cuando se encuentre enfrente de un paciente, no podrá recurrir a fórmulas de memoria. Y además, la práctica hace al maestro.

La construcción de escenarios imaginarios es distinta en niños, y en adultos. Con los adultos las sugestiones deben de ser creíbles, enfocadas, y con sentido de acuerdo al rango vivencial del paciente.

Se puede recurrir al parpadeo sincronizado en niños, pero no es indispensable, cualquier forma de captar su atención puede ser válida. En adultos se puede recurrir a la fijación de la mirada en un punto fijo, o en los ojos del hipnólogo, o simplemente guiarle por medio de la palabra.

La respiración profunda o superficial, la relajación física, la captación de la atención, y la construcción de escenarios imaginarios, es la tendencia de procedimiento usual para ejecutar la hipnosis. A veces no se cumple con este orden debido a las características de cada paciente.

La hipnosis es reportada como útil en gran variedad de padecimientos, hábitos y acciones asertivas, pero se deben de atender solo aquellos estudios bien controlados desde lo experimental, y aquellos de buen fundamento teórico. Tanto valor tiene un estudio controlado experimentalmente, como uno casuístico, lo importante es investigar los fenómenos psicosomáticos involucrados.

La aplicación de la técnica hipnótica, puede ser aplicada de emergencia a un paciente con dolor agudo, siempre y cuando se cuente con el apoyo médico, pero de no ser posible, se 
debe de ayudar al paciente a tranquilizarse y a lidiar con el dolor mientras se asiste médicamente. En el caso del dolor crónico, el paciente usualmente ha sido tratado por médicos previamente, y por el ello intervienen otros factores, que bien estudiados en la entrevista clínica, pueden facilitar la intervención hipnótica, incluso sin la presencia directa del médico.

Si el paciente se encuentra internado en un hospital, el hipnólogo puede entrevistarlo para conocer su historia clínica y psicológica, con lo cual podrá diseñar mejor su estrategia de intervención hipnótica.

El que un paciente pueda auto-hipnotizarse, requiere de un previo aprendizaje por medio de la heterosugestión, además, el paciente debe de estar fortalecido en algunas de sus funciones yoicas, y en especial en su capacidad de diálogo interno.

La valoración del dolor requiere de mayor investigación, tanto en el diseño y aplicación de registros objetivos y métricos, como de técnicas no farmacológicas. Ambas valoraciones pueden y deben de complementarse.

\section{CONCLUSIÓN}

La hipnosis es un instrumento útil para el control del dolor, así como de la ansiedad. Debemos de incluir el malestar del paciente, pues esta concepción amplía la acción de la hipnosis más allá del control, y nos permite acceder al manejo, dimensión que involucra el significado que tiene para el paciente, tomando en cuenta su construcción histórica como persona.

Aunque todos los investigadores coinciden en los beneficios de la hipnosis y otras técnicas para el control del dolor y la ansiedad, en ciertos momentos, existe cierta ambigüedad sobre los límites operativos y conceptuales entre la relajación, la sugestión y la hipnosis. En mi 
investigación con niños quemados (Vargas, 2000) señalé que un procedimiento útil en el trabajo terapéutico era el denominado como RIH, y aunque la secuencia operativa no siempre se puede cumplir, aún así las experiencias clínicas demostraron ese traslape, o más bien, ese nivel pragmático de integración. La experiencia indica, que no se puede discriminar tan fácilmente la esfera de influencia de cada una de ellas, tal vez se deba a que están intrínsecamente juntas, incluso se pueden ejecutar ejercicios de reestructuración cognitiva dentro de un trance hipnótico, aunque no se puede decir lo contrario.

La experiencia indica, que la intervención hipnótica con niños no requiere del factor fe, tal vez porque los infantes siempre confían en los adultos, o-y porque la sugestión hipnótica revivencia la experiencia vertical y significativa con sus padres o figuras de autoridad.

La valoración del dolor con instrumentos objetivos y subjetivos, puede complementarse con una lectura teórica ecléctica de la mente humana. Pero la aplicación de la hipnosis en campos no clínicos (del dolor), deja abierta la construcción y lectura de la sugestión y la disociación hacia el contenido onírico, y aquí pueden intervenir otras disciplinas como el psicoanálisis, la literatura, el arte.

\section{BIBLIOGRAFÍA}

Alvarenga, M. El hipnotismo, San José: Editorial Porvenir, S.A., 1996.

Ballantyne, C. J. / Borssok, D. Dolor posoperatorio. En: Borsook, D. / LeBel, A. / Bucknam, M., eds. Massachusetts General Hospital Tratamiento del dolor. Madrid: Marbán, S. L.: 1999. pp. 243-265.

Barone, E. / Mandorla, J. ABC de la hipnosis, Gerona: Tikal ediciones, 1994.

Benians, R.C. The influence of parental visiting on survival and recorvery of extensively burned children. Burns 1988; 14: pp. 31-34.

Borenstein, D.G./ Seidman, D.S. / Tsur, H. Burn patients use of autohypnosis: making a painful experience bearable. Burns, 1990; 16: pp. 441-444.

Bourne, R. 2 day basic hypnosis training workshop (14 contact hours). The Virginia Ericksonian Institute, April 1-2, 1994: San José. Costa Rica.

Bowden, Ch. / Burstein, A. Bases psicosociales de la atención médica, Primera edición, México D.F.: Editorial Limusa, 1990. 
Cautela, J. / Groden, J. Manual práctico para adultos, niños y educación especial, Barcelona: Libros universitarios y profesionales Martínez Roca, 1985.

Cordero, T. / Vargas, W. Planteamientos básicos sobre la intervención del psicólogo en una unidad de quemados. Revista Costarricense de Psicología 1991; 9: pp. 5763.

Cruzado, J. / Labrador, F. / Puente, M. / Vallejo, M.A. El dolor. En: Fuentenebro, F. / Vásquez, C., eds. Psicología médica , psicopatología y psiquiatría. España: Mc Graw-Hill; 1990. pp.579-595.

Chen, E. / Joseph, M. / Zeltzer, L. Intervenciones conductuales y cognitivas en el tratamiento del dolor. Clínicas Pediátricas de Norte América 2000; 3: pp. 551-564.

Dauber, A. / Bucknam, M. Dolor en el paciente quemado. En: Borssok, D./ LeBel, A. / Bucknam, M., eds. Massachusetts General Hospital Tratamiento del dolor. Madrid: Marbán, S.L.: 1999. pp. 266-269.

De La Fuente Muñiz, R. Psicología médica, Octava edición, México, D.F.: Fondo de Cultura Económica, 1969.

Edwards, A. Tratamientos no farmacológicos del dolor. En: Borssok, D. / LeBel, A. / Bucknam, M., eds. Massachusetts General Hospital Tratamiento del dolor. Madrid: Marbán, S.L.: 1999. pp.105-111.

Fisman, S. / Greenberg, D. Aspectos psicosociales en el tratamiento del dolor. En: Borssok, D./ LeBel, A. / Bucknam, M., eds. Massachusetts General Hospital Tratamiento del dolor. Madrid: Marbán, S.L.: 1999. pp. 379-393.

Freud, S. Obras Completas, Buenos Aires: Amorrortu editores, 1976.

Gindes, B. Nuevos conceptos sobre el hipnotismo, Buenos Aires: Editorial Psique, 1972.

Hadley, J. / Staudacher, C. Hipnosis. Camino para el cambio, Barcelona: Ediciones Robinhook, S.L., 1994.

Henry, D. / Foster, R. Tratamiento del dolor por quemaduras. Clínicas Pediátricas de Norte América 2000; 3: pp. 725-743.

Hernández, R. / Rodríguez, S. Ejercicio de relajación para niños de Koeppen, San José: Ministerio de Salud. Departamento de Salud Mental, S.F.

Hewitt, W. Hypnosis. A power program for self-improvement changing your life and helping others, St. Paul, Minnesota: Ilewellyn Publications, 1989.

Holroyd, J. Hipnosis, tratamiento del dolor clínico. IJCEH 1996; January, S.P.

Holroyd, J. Seminario-Taller sobre hipnosis y manejo del dolor en niños. Hospital Nacional de Niños “Dr. Carlos Sáenz Herrera”. San José, Costa Rica, Marzo, 1993.

Kavanagh, K. Burned children. J.Am. Chil. Adolesc. Psychiatric 1990; 29: pp. 487 (Letters to the Editor).

Kelly, J. / Lynch, T. Técnicas psicológicas en el tratamiento del dolor. En: Raj Prithvi, P., eds. Tratamiento práctico del dolor. Madrid: Mosby División de Times,

Mirror de España, S.A.; 1994. pp. 650-657.

Kittelberger, K.P./ LeBel, A. / Brossok, D. Valoración del dolor. En: Borssok, D. / LeBel, A. / Bucknam, M., eds. Massachusetts General Hospital Tratamiento del dolor. Madrid: Marbán, S.L.; 1999. pp. 26-44.

Kroger, W. Hipnosis clínica y experimental, Tercera edición, Buenos Aires: Editorial 
Glem, S.A., 1974: tomos 1-2-3.

LaCross S. / Soumekh, S. Rehabilitación del dolor crónico. En: Borssok, D./ LeBel, A. / Bucknam, M., eds. Massachusetts General Hospital Tratamiento del dolor. Madrid: Marbán, S.L.: 1999. pp.194-206.

Long, C. / Cope, O. Emotional problems of burned children. New England journal of Med 1961; 264: pp. 1121-1127.

Martínez, P./ Asís, M. Hipnosis, teoría, métodos y técnicas, La Habana: Editorial Científico-Técnica, 1989.

Mooney, N. Control del dolor en pacientes ortopédicos. Clínicas de Enfermería de Norte América 1991; 1: pp. 71-85.

Olness, K. Hynotherapy: a cyberphysiologic strategy in pain manegement. The pediactric clinics of North America 1989; 36: pp. 873-884.

Osgood, P. / Szyfelbein, S.K. Management of burn pain in children. The Pediatric Clinics of North America 1989; 36: pp. 1001-1013.

Patterson, D. / Everett, J. / Burns, L. / Marvin, J. Hypnosis of the treatment of burn pain. Journal of Consulting and Clinical Psychology 1992; V. 60: 713-717.

Peebles-Kleiger, M. The use of hypnosis in emergency medicine. Emergency Medicine Clinics of North America, 2000; 18: pp. 327-338.

Putnam, F. Dissociative disorders in children and adolescents. Psychiatric Clinics of North America 1991; V. 14: pp. 519-529.

Rivlin, E. The psychological trauma and management of severe burns in children and adolescents. British Journal of Hospital Medicine 1988; V. 40: pp. 210-215.

Rusy, L. / Weisman, S. Tratamientos complementarios para la atención del dolor agudo. Clínicas Pediátricas de Norte América 2000; 3: pp. 629-640.

Salas, I. / Chan Suen, K.H. / Wu Chen, W.Ch. Manejo del dolor en el cáncer, Primera edición, San José: Editorial de la Universidad de Costa Rica, 1997.

Schechter, N. The undertreatment of pain in children: on overview. Pediatric Clinics of North America 1989; 36: pp. 781-794.

Selbst, S./ Henretig, F. The treatment of pain in the emergency deparment. Pediatr Clin North Am 1989; 36: pp. 965-978.

Stoddard, F. / Norman, D. / Murphy, M. / Bearsdslee, W. The authors reply (to Kavanagh). Am. Child Adolesc. Psychiatry 1990; 29: pp. 487.

Stokvis, B./ Wiesenhütter, E. Técnicas de relajación y de sugestión, Barcelona: Editorial Herder, 1983.

Tucker, K. / Virnelli, F. The use of hypnosis as tool in plastic surgery. Plastic and Reconstrutive Surgery 1985; 76: pp. 140-145.

Van der Does, J. W. / Van Dyck, R. ¿Does hipnosis contribute to the care of burn patients?. General Hospital Psychiatriy 1989; 11: 119-124.

Vargas, W. Investigación de los fenómenos psicológicos en el diagnóstico del Síndrome de estrés post-traumático con una metodología dirigida hacia el descubrimiento. Aplicación de la técnica hipnótica a cinco casos de niños quemados. Tesis, Universidad de Costa Rica, Ciudad Rodrigo Facio: San Pedro de Montes de Oca, 2000.

Wolter, U. / Ahern, D. K. Procedimientos no farmacológicos: aspectos psicosociales del dolor. En: Borssok, D. / LeBel, A. / Bucknam, M., eds. Massachusetts General Hospital Tratamiento del dolor. Madrid: Marbán, S.L.: 1999. pp.121133. 
Wright, B. / Drummond, P. D. Rapid induction analgesia for the alleviation of procedural pain during burn care. Burns, 2000; 26: pp. 275-282.

Yans, A. El hombre nuevo, Guatemala: Instituto Guatemalteco de Psicología e Hipnosis Clínica, 1974.

Zeltzer, L. / Jay, S. / Fisher, D. The management of pain associated with pediatric procedures. Pediatr Clin North An 1989; 36: pp. 941-964. 